\title{
SEAFLOOR OBSERVATORY SCIENCE
}

\author{
Paolo Favali $^{(1)}$, Roland Person ${ }^{(2)}$, Chris R. Barnes ${ }^{(3)}$, Yoshiyuki Kaneda ${ }^{(4)}$, John R. Delaney ${ }^{(5)}$, Shu-Kun Hsu ${ }^{(6)}$ \\ ${ }^{(1)}$ Istituto Nazionale di Geofisica e Vulcanologia (INGV), Via di Vigna Murata, 605, Roma (Italy), \\ Email: emsopp@ingv.it \\ (2) IFREMER (French Institute for Exploitation of the Sea/Institut Français de Recherche pour l'Exploitation de la Mer) \\ BP 70, 29280 Plouzané, France, Email: esonet-coordinator@ifremer.fr \\ ${ }^{(3)}$ University of Victoria, PO Box 1700 STN CSC, Victoria BC V8W 2 Y2 Canada, Email: crbarnes@uvic.ca \\ (4) Japan Agency for Marine-earth Science and Technology, 2-15 Natsushima, Yokosuka, Kanagawa, 237-0061, Japan, \\ Email: kaneday@jamstec.go.jp \\ (5) University of Washington, 7600 Sand Point Way NE, Seattle, WA 98115, USA, Email: jdelaney@u.washington.edu \\ ${ }^{(6)}$ Institute of Geophysics, National Central University, No.300, Jhongda Rd., Jhongli City, Taoyuan County 32001, \\ Taiwan (R.O.C.), Email: hsu@ncu.edu.tw
}

\begin{abstract}
This paper deals with a new emerging science the "Seafloor Observatory Science". It is evolved rapidly over the last two decades by means of new projects and programmes towards the establishment of permanent underwater networks. The main on-going initiatives at global scale are presented for Canada (NEPTUNE North East Pacific Time-series Underwater Networked Experiments), USA (OOI - Ocean Observatories Initiative), Japan (DONET - Dense Oceanfloor Network system for Earthquakes and Tsunamis), Taiwan (MACHO - Marine Cable Hosted Observatory) and Europe (through ESONET-NoE - European Seas Observatory NETwork-Network of Excellence and recently with the infrastructure project EMSO European Multidisciplinary Seafloor Observatory). Moreover, the scientific motivations for seafloor observatories and their main architecture are discussed. Finally, the applications and opportunities of cabled observatories beyond those in ocean science research, technology and data services are outlined. It is important to recognise that the advent of cabled ocean observatories heralds in a new era of ocean exploration and interpretation, which will make profound contributions to socio-economic benefits, public policy formulation, and public education and engagement.
\end{abstract}

\section{INTRODUCTION}

The ocean exerts a pervasive influence on Earth's environment. It is therefore important that we learn how this system operates. Understanding the ocean, and the complex physical, biological, chemical, and geological systems operating within it, is a challenge for the opening decades of the $21^{\text {st }}$ century. The establishment of a global network of seafloor observatories will help to provide the means to accomplish this goal. A fully comprehensive definition of the term "seafloor observatories" was given for the first time by the NRC (National Research Council) report "Illuminating the Hidden Planet. The future of Seafloor Observatory Science”, where we can read: "...an unmanned system, at a fixed site, of instruments, sensors, and command modules connected to land either acoustically or via a seafloor junction box to a surface buoy or a fibre-optic cable..." [1] The establishment of a global network of seafloor observatories will provide powerful means to understand the ocean and the complex physical, biological, chemical, and geological processes. Many large-scale projects have been planning to establish permanent seafloor networks at International level. Canada, USA, Japan, Taiwan and Europe are the major actors. In Canada the major component of this effort is NEPTUNE (North East Pacific Time-series Underwater Networked Experiments) [2] and VENUS (Victoria Experimental Network Under the Sea) [3]. In the United States, the OOI (Ocean Observatories Initiative) a NSF (National Science Foundation) Division of Ocean Sciences program [4] has launched the RSN (RegionalScale Nodes) [5]. Japan started in 1978 to manage cabled seafloor observatories for scientific use, and particularly for real-time monitoring for seismic and tsunami warning. One of the most recent Japanese projects is DONET (Dense Oceanfloor Network system for Earthquakes and Tsunamis) [6]. In Taiwan the project MACHO (Marine Cable Hosted Observatory) recently started and is a submarine cabled observatory offshore of eastern part of the island with the main purpose to establish offshore seismic stations, to provide early warning of earthquakes and tsunamis, and to monitor submarine volcanic activity [7]. In Europe the effort to build a seafloor observation infrastructure have been supported by the EC (European Commission) first through ESONET-NoE (European Seas Observatory NETwork-Network of Excellence), aimed at gathering together the community interested in multidisciplinary ocean observatories [8], and more recently with the EMSO-PP project (European Multidisciplinary Seafloor Observatory-Preparatory Phase), aimed at establishing the legal entity charged of the construction and management of the EMSO infrastructure. The European-scale network of seafloor observatories widely distributed for long-term monitoring of 
environmental processes related to ecosystem life and evolution, global changes and geo-hazards [9].

\section{SCIENTIFIC MOTIVATION FOR SEAFLOOR OBSERVATORIES}

In recent decades ocean, Earth and planetary sciences have been shifting from a discontinuous, expeditionary mode toward a mode of sustained in situ observations. This change in the mode of investigation stems from the realisation that Earth and its oceans are not static, but are dynamic on many time and space scales, not just the short-time scales involved in catastrophic events. A scientifically powerful component of the observatory concept is the long time-series collection of multiple variables at a fixed location. These multidisciplinary datasets will enable the enhancement of more traditional methods, giving strong benefits to many disciplines.

Seafloor observatories will thus offer earth and ocean scientists new opportunities to study multiple, interrelated scientific processes over time scales ranging from seconds to decades, such as: a) episodic processes; b) processes with periods from months to several years; c) global and long-term processes. Episodic processes include, for instance, deep-ocean convection at high latitudes, volcanic eruptions, earthquakes, tsunamis, and biological, chemical and physical impacts of storm events. The establishment of an observatory network, covering from the surface of the ocean along with the water column to the seabed beneath, will be essential to investigate global processes, such as the dynamics of the oceanic lithosphere and thermohaline circulation, and their reciprocal interactions.

Much of seafloor observatory research is indeed interdisciplinary in nature and has the potential to greatly advance relevant scientific sectors, such as: 1) the role of the ocean in climate; 2) dynamics of oceanic lithosphere and imaging the Earth's interior; 3) fluids and life in the ocean crust; 4) coastal ocean processes; 5) turbulent mixing and biophysical interactions; and 6) ecosystem dynamics and biodiversity [10].

The Seafloor Observatory Science addresses Interdisciplinary research priorities in:

- Physical oceanography: water mass characterisation, water column processes, thermodynamics, ice cover, climatology, and impacts on climate change.

- Geosciences: transfer from Earth's interior to the crust, hydrosphere and biosphere, fluid flow and gas seepage through sediments and gas hydrate, nonliving resources, sediment transfer to deep sea and climate change.

- Geo-hazards: earthquake and tsunami hazard, volcanic hazard, slope instability and failure.
- Biogeochemistry: global carbon cycle and elemental cycling within the ocean through both physical and biological processes, and ocean acidification.

- Marine ecology: distribution and abundance of sea life, ocean productivity, biodiversity, ecosystem function, living resources, and climate feedbacks.

\section{SEAFLOOR OBSERVATORY ARCHITECTURE}

The principal characteristic of a seafloor observatory is a two-way communication between platforms and instruments and shore. During the last 30 years deep-sea investigations moved from scarce observations to continuous measurements of a wide set of parameters in selected areas. Seafloor observatories are characterised by the following basic elements: a) abundant power; b) sensor networks; c) high bandwidth communications; d) possibility to be remotely reconfigured; e) accurate positioning; f) data acquisition procedures compatible with those of shore observatories.

Seafloor observatory is an unmanned station, capable of operating for decades on the seafloor, supporting the operation of a number of instrumented packages related to various disciplines. According to the capacity of communication, the seafloor observatories can have the following possible configurations:

1) Stand-alone observatory: Observatory in stand-alone configuration for power, using battery packs, and with limited capacity of connection, using, for instance, capsules or an acoustic link from the surface, which can transfer either status parameters or a very limited quantity of data.

2) Platform connected observatory:

a) Acoustically linked observatory able to communicate by acoustics to an infrastructure, such as a moored buoy or another observatory;

b) Tethered observatory constituted of a sea bottom cabled segment connected to a surface buoy with satellite links capacities. This type is strongly depending on the environmental constraints, such as water depth or protected conditions.

3) Cabled Observatory: Observatory having as infrastructure a submarine cable directly connected to shore for power and real-time data transmission. The cables to be used can be retired cables, dedicated cables or shared cables devoted to other scientific activities.

\section{NEPTUNE CANADA}

The NC (NEPTUNE Canada) Project [2] completed most of the installation of the world's first regional cabled ocean observatory in late 2009, with instrumentation at Endeavour to be completed in 2010, off Canada's west coast. The observatory comprises five 
main observatory sites (ranging from $100 \mathrm{~m}$ coastal to $2700 \mathrm{~m}$ abyssal plain water depths) located along an 800-km backbone cable loop (Fig. 1).

In bringing abundant power and high bandwidth to diverse ocean environments, establishing a vast data archive, and enabling multidisciplinary interactive realtime experiments, the ocean sciences will be transformed. The NC project complements other cabled ocean observing systems recently established or in the planning stages. Initial operational funding was recently received from the NSERC (Natural Sciences and Engineering Research Council of Canada), CFI (Canada Foundation for Innovation), BC Ministry of Advanced Education, CANARIE (Canadian Network for the Advancement of Research Industry and Education) and the UVic (University of Victoria). UVic leads a consortium of 12 Canadian universities, with scores of participating scientists that include many government and international scientists. $\mathrm{NC}$ has over 30 full-time staff plus consultants. UVic also hosts the coastal VENUS [3], with ONC (Ocean Networks Canada) [11] providing project management oversight and support.

Over the past decade, the NC project was developed in collaboration with the US, particularly the University of
Washington, and now more formally with the OOI [4] that was established by the NSF. OOI has received its main infrastructure funding in September 2009, which includes a RSN array on the southern Juan de Fuca plate [5], complementing that of $\mathrm{NC}$, and achieving interoperability through the cyber-infrastructure. The $\mathrm{NC}$ observatory will investigate a great diversity of Earth/ocean processes, phenomena and events, with instruments deployed in the subsurface (boreholes), on the seabed, and buoyed through all or part of the water column (powered vertical profiler and fixed buoys). More than 130 instruments will host several hundred sensors. The observatory is designed to facilitate realtime observations and experiments that will establish a vast data archive, allowing interactive participation with both the instruments and the archive by the scientists. The observatory is also designed and located to address a wide spectrum of research questions. Experiments focus on: earthquake dynamics and tsunami hazards; fluid fluxes in the ocean crust and sediments, including gas hydrate deposits; ocean and climate dynamics, including acidification, nutrient fluxes and impacts on biota; deep-sea ecosystems dynamics; and applied engineering and computer science research.

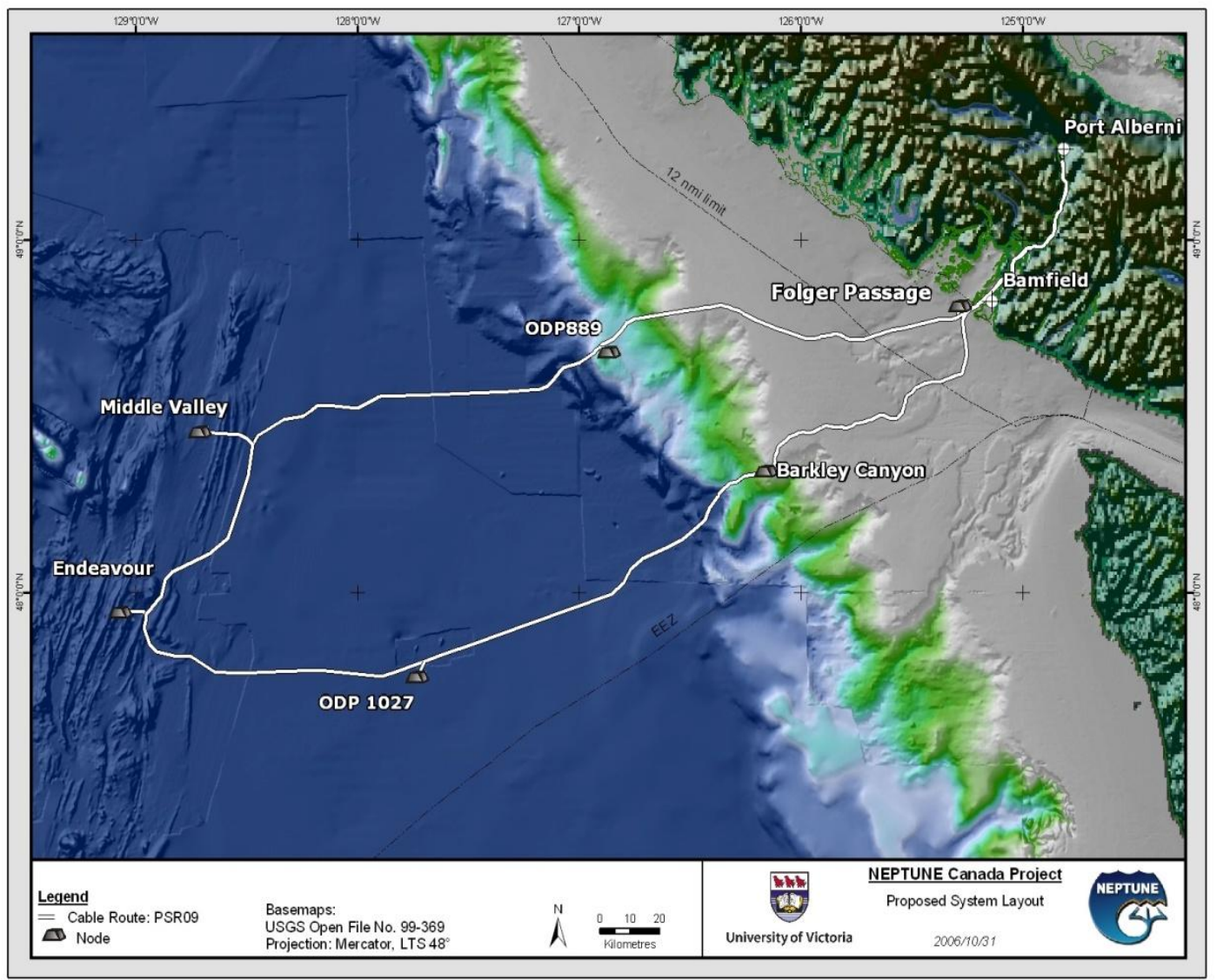

Figure 1. The NEPTUNE Canada backbone cable loop 
The DMAS (Data Management and Archiving System) has been developed in-house, using the Agile development methodology to deliver frequent, incremental versions of the system. The need for a software system to support NC underwater infrastructure is critical. The software serves as an interface between users and the cable observatory and responds to a triple mandate:

- acquire data from various instruments and sensors underwater;

- provide life-time storage and redistribution capabilities for all data;

- allow duly authorised users to remotely and interactively control experiments.

There is good collaboration between NC and other observatory groups noted in this paper: a Memorandum of Understanding has been established with each, there are monthly teleconferences with the $\mathrm{NC}$ and OOI executive groups. In particular, there is daily collaboration between NC and VENUS and also with MARS (Monterey Accelerated Research System) [12]. There is considerable effort being made to ensure interoperability with other observatories, especially with the use of data.

\section{OCEAN OBSERVATORIES INITIATIVE}

OOI is a NSF Division of Ocean Sciences program that focuses the science, technology, education and outreach of an emerging network of science driven ocean observing systems [4]. OOI will construct a networked infrastructure of science-driven sensor systems to measure the physical, chemical, geological and biological variables in the ocean and seafloor. Greater knowledge of these variables is vital for improved detection and forecasting of environmental changes and their effects on biodiversity, coastal ecosystems and climate.

OOI infrastructure is based on four components: 1) global; 2) regional; 3) coastal; 4) cyber-infrastructure:

1) Global The global scaled component includes a network of buoys (GSN-Global-Scale Nodes). These buoys will support sensors for measurement of airsea fluxes of heat, moisture and momentum; physical, biological and chemical properties throughout the water column, and geophysical observations made on the seafloor. The OOI design process has identified four strategic high-latitude sites for initial GSN: the South Pacific off Chile, the South Atlantic in the Argentine Basin, the Irminger Sea in the sub-polar North Atlantic and Ocean Station Papa in the Gulf of Alaska (Fig. 2a).

2) Regional The focus of regional scaled ocean observatories (RSN-Regional-Scale Nodes) is to provide long-term and adaptive access to measurements of geological and oceanographic phenomena on regional scales. A regional cabled observatory has been proposed to observe a single tectonic plate, facilitating study of all of the major types of plate boundaries - from spreading centres to transform faults and subduction zones - together with the hydrothermal regimes that they encompass (Fig. 2b).

3) Coastal The OOI coastal scale component (CSNCoastal-Scale Nodes) will enhance and expand upon existing coastal observing assets, providing unique and extended research approaches to many complex problems in the coastal environment. These include the extreme variability of large and mesoscale coastal ocean circulation, material mass balance (e.g., nutrient and carbon fluxes across the continental shelves between land and ocean), ecosystem stability and change, coastal morphology, beach erosion and other anthropogenic dimensions of land-sea interaction. The CSN initial stage consists of two elements: a long-term Endurance Array off the Pacific Northwest and a relocatable Pioneer Array in the Middle Atlantic Bight (Fig. 2a).

4) Cyber-infrastructure This component (CI-Cyberinfrastructure) provides the common operating infrastructure connecting and coordinating the operations of the three OOI observatories with the scientific and educational pursuits of the oceanographic research communities. The CI will transport real-time data streams at up to 1 gigabit per second from a variety of ocean-dwelling sensors and other instruments. The data will be available in real time via dedicated, high-speed Internet links.

The RSN concept [5] is based on the premise that many globally significant planetary phenomena operate at or below the regional scale. Thorough 4-D examination of the full spectrum of Earth and ocean process associated with at least one regional-scale system will generate major new insights into all such systems. A regional observatory has an important role to play in integrating the components of the OOI by seamlessly spanning the coastal to global components with a large and adaptable footprint. The region associated with Juan de Fuca Plate in the northeast Pacific Ocean was chosen for the first RSN study site to attract the broadest possible user base to this oceanographic research platform and to minimise cost. The footprint encompasses many important watercolumn, sedimentary, and biological phenomena that occur throughout the global ocean, as well as a broad spectrum of plate-tectonic processes. The University of Washington is leading the effort to develop the RSN. The RSN, together with the NEPTUNE Canada network, will form the world's first ocean observatory to span a tectonic plate. The facility will provide a constant stream of data in real time from throughout the water, 

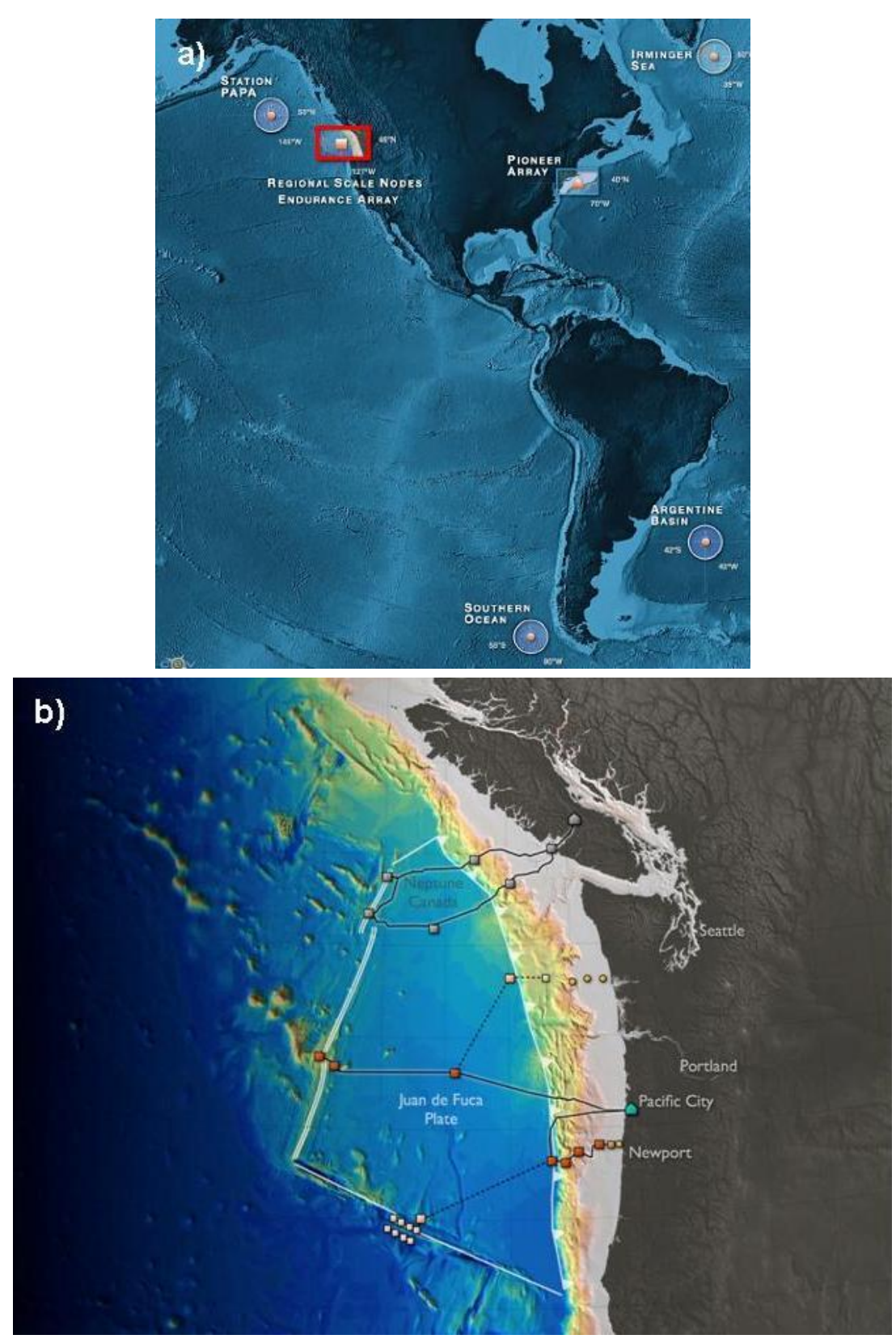

Figure 2. a) The different OOI components are indicated: GSN (Global-Scale Nodes) with circles, CSN (Coastal-Scale Nodes) with light blue rectangle, $R S N$ (Regional-Scale Nodes) with red rectangle (detailed map in $2 b$ ). $b$ ) The $R S N$ together with NEPTUNE Canada network, the solid lines (cables) are funded, the dashed lines are potential expansions

on the seafloor, and below the seafloor associated with the Juan de Fuca tectonic plate (Fig. 2b).MARS is a test bed for the OOI RSN as a critical step in mitigating the risks associated with developing this next generation observing system [12].

\section{DONET}

The Nankai trough is well known as mega thrust earthquake seismogenic zone. There are three mega thrust rupture zones such as the Tokai, Tonankai and Nankai seismogenic zones. In these rupture areas, mega thrust earthquakes over M8 are occurring with an interval of 100-200 years. Results of mega thrust earthquake recurrence cycle simulation show that the first ruptures are occurring around the Tonankai earthquake rupture zone in each recurrence cycle. These results are consistent with past two earthquakes in 1944/1946 and 1854. In two earthquakes, Tonankai earthquake occurred ahead of Nankai and Tokai earthquakes. The probability of next Tonankai earthquake recurrence is estimated as $60-70 \%$ within 30 years. 
Based on structural research, observational research and simulation researches, we proposed and have been starting to deploy the dense ocean floor observatory network system DONET [6] around the Tonankai seismogenic zone, to monitor crustal activities using broadband seismometers, accelerometers and precise pressure gauges (Fig. 3).

The DONET observatory system will be the one of most advanced scientific tools to understand the mega thrust earthquakes around the Nankai trough. This advanced dense ocean floor observatory network system has useful functions and purposes as follows:

- redundancy, extension and advanced maintenance system using the looped cable system, junction boxes and ROV/AUV (Remotely Operated Vehicle/Autonomous Underwater Vehicle);

- development of ROV for the 10-km cable extension and heavy weight operation; many different sensors to observe broadband range phenomena such as long-period tremors, lowfrequency earthquakes and strong motion of mega thrust earthquakes over M8;

- fast evaluation and notification for earthquakes and tsunamis, the ocean floor network data will contribute to the early warning system for disaster mitigation that JMA (Japan Meteorological Agency) is starting to develop;

- to provide observed data such as ocean floor deformation derived from pressure gauges to improve the simulation and modelling researches about the mega thrust earthquakes;

- to understand the interaction between the crust and upper mantle around subduction zone.

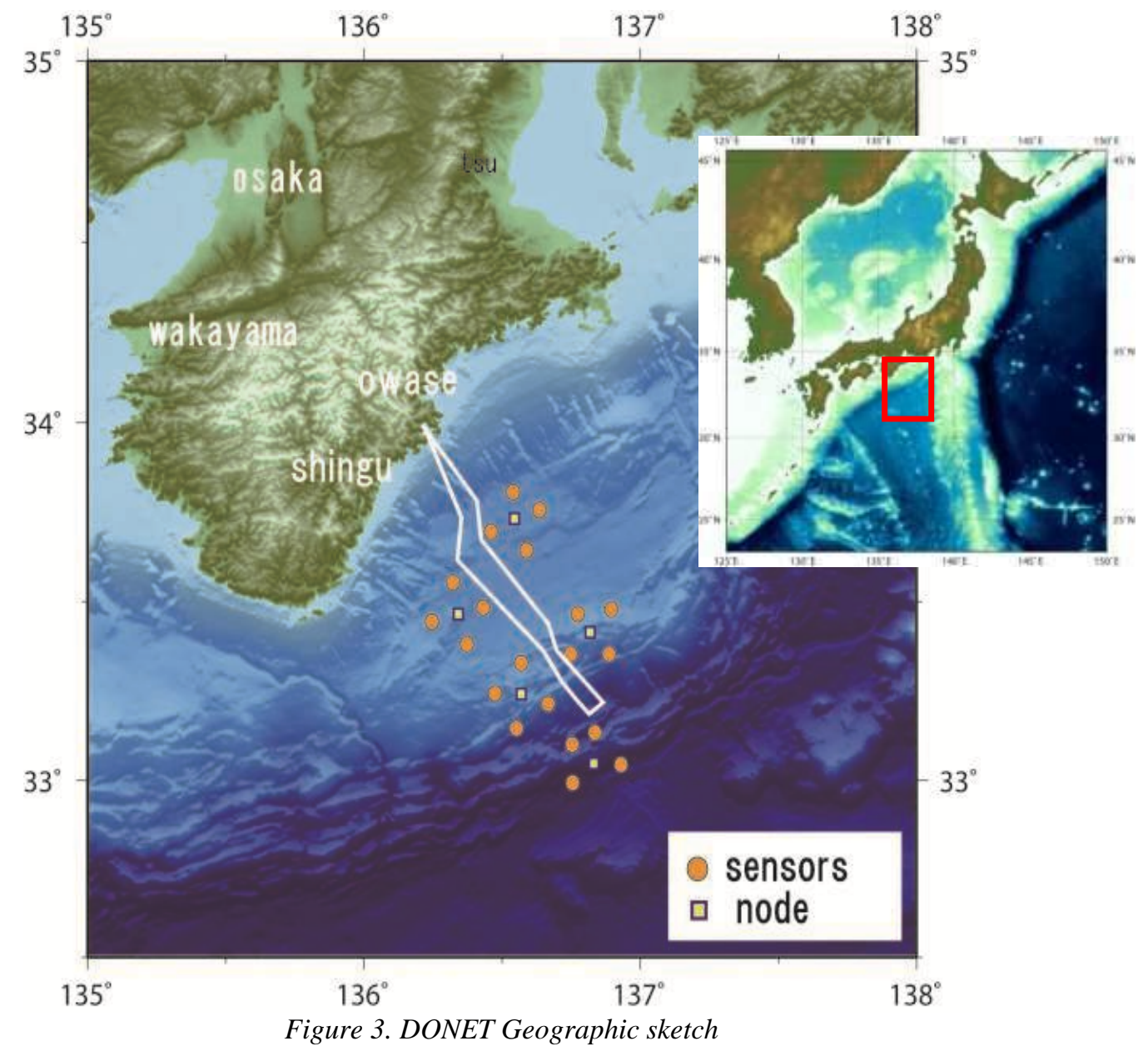

\section{7. МАСНО}

Taiwan is an island uplifted along the border of the Eurasian plate and the Philippine Sea plate and is a part of the Circum-Pacific seismic belt. Because of collision and subduction processes, there are about 18,000 earthquakes occurring in and around Taiwan every year. 
Especially, there are more than $70 \%$ of earthquakes occurring in the offshore area of eastern Taiwan. As a consequence, seismic hazard is one of the major natural disasters in Taiwan. It is therefore essential for Taiwan to seek reliable and fast monitoring to mitigate earthquake damages. Hence, the CWB (Central Weather Bureau) of Taiwan needs to improve the efficiency for monitoring these offshore earthquakes, including reduce the earthquake response time and enhance the accuracy of earthquake epicentre determination. For that, the CWB had proposed the MACHO project [7] to implement a cable-based observational system off eastern Taiwan in 2007.

For a first phase, the MACHO project is a 3-year project from 2007 to 2009. In our plan, the submarine cable will be landed at Toucheng station in the Ilan plain, northeast Taiwan (or westernmost of Okinawa Trough). The Toucheng shore station is not far from the Taipei headquarter of CWB. Originally, the cable length was planned for $500 \mathrm{~km}$, five nodes and a loop configuration. The whole $\mathrm{MACHO}$ project will be realised step by step. For the moment, the CWB will set up the cabled seafloor observatory of the first phase MACHO project as a test study. To date, the submarine cable length could be only $50-\mathrm{km}$ long and one node (Fig. 4). From an observational node short-period and strong motion earthquake sensors and pressure gauges will be installed. Besides, the CTD (Conductivity, Temperature and Pressure) and ADCP (Acoustic Doppler Current Profiler) sensors are also considered.

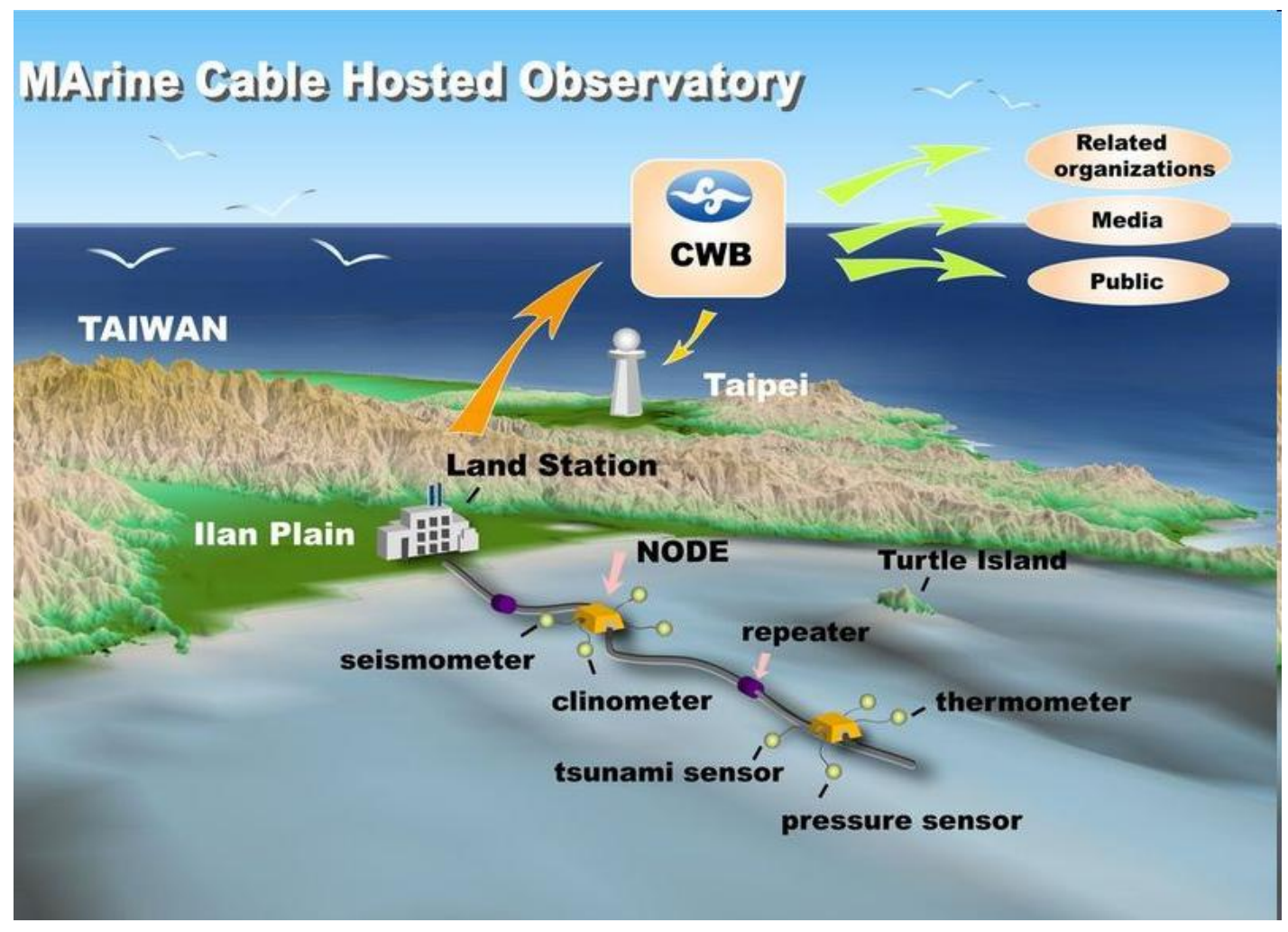

Figure 4. MACHO scheme

\section{EMSO AND ESONET-NOE}

EMSO is the European large-scale infrastructure composed of seafloor observatories for long-term monitoring of environmental processes related to ecosystems, climate change and geo-hazards [9]. This infrastructure is included in the ESFRI Roadmap (European Strategy Forum on Research Infrastructures) [13]. EMSO nodes are placed in specific marine sites on the European Continental Margin from the Arctic to the Black Sea through the Mediterranean Basin (Fig. 5). These sites were selected within EC projects, the previous ESONET-CA (European Seafloor Observatory NETwork-Concerted Action, 2002-2004) [14] and the on-going ESONET-NoE (2007-2011) [8]. The design and development of the nodes depend upon: geographical location, scientific requirements, operational requirements and available resources. Two basic models can be envisaged for the nodes: standalone acoustically linked observatory and cabled observatory. However, hybrid configurations could be adopted according to the site characteristics. The nodes will be equipped with a common set of sensors for basic measurements and further sensors for specific purposes. 
EMSO will constitute the sub-sea segment of GMES (Global Monitoring for the Environment and Security) [15] and GEOSS (Global Earth Observation System of Systems) [16].

EMSO is presently in the Preparatory Phase (EMSOPP) with a project of EC-FP7. This project will establish the legal entity EMSO, which is able to manage the scientific, technical, logistic and administrative components of the infrastructure. EMSO-PP has started in April 2008 and will run for 4 years. Presently 12 Countries are involved in EMSO-PP: Italy (coordinator), Sweden, Norway, Ireland, United Kingdom, the Netherlands, Germany, France, Portugal, Spain, Greece and Turkey [9].

The inclusion of the EMSO infrastructure in the ESFRI list [13] is based on the development of EC projects dating back to ' 90 that aimed at realising and validating seafloor observatory and network prototypes. The establishment of a multidisciplinary network of seafloor observatories is currently supported by the EC through the ESONET-NoE [8], which comprises more than 50 European universities, research institutes, companies involving 14 countries and about 300 scientist, engineers and technicians. This project aims at boosting the integration of the European Ocean Sciences community interested in observatories. ESONET-NoE is building up the integrated teams, the standards, the methods and the scientific cooperation practices for the use of the EMSO infrastructure. This is reflected in the establishment of the ESONET Label, which defines the prescribed standards and interoperability requirements for potentially participating sites. Standards will enable compatibility, integration, and interoperability between different sub-systems developed independently by a variety of investigators on a more cost-effective basis, also increasing reliability [17].

In most of the EMSO/ESONET nodes activities are currently running preliminary to future permanent installations. These activities are supported by National and European funded projects. For instance, ESONET is funding some DMs (Demonstration Missions) [8] in Arctic, Nordic Sea, Porcupine Abyssal Plain, Azores Islands, Iberian Margin, Ligurian Sea, Western Ionian Sea, Hellenic Arc and Marmara Sea (Fig. 5). In particular, the Western Ionian Sea node (NEMO-SN1: Neutrino Mediterranean Observatory-Submarine Network 1) hosts a first nucleus of seafloor platforms cabled connected to the shore since 2005 [18]. NEMOSN1 is the first real-time seafloor observatory in Europe.
ESONET/EMSO will allow an understanding of:

- the environmental processes as interaction between the geo-, bio-, and hydro-sphere;

- the temporal evolution (short-, medium- and longterm, periodic and episodic events) of the oceanic circulation, earth processes, deep-sea environment and ecosystems.

They will take advantage of the synergies between the scientific community and the industry and will contribute to a significant improvement of marine technologies and the development of strategies for improving European capacities and competitiveness in ocean sciences and technologies.

The rationale for EMSO infrastructure is based on the following issues:

- Scientific: the sea as key element to understand the dynamics and evolution of the Earth components.

- Technological: maturity of methodology and approaches for deep-sea observations (i.e., long-term time series).

- Strategic: environmental control for preservation (habitat, biodiversity), mitigation of hazards, new resources exploitation.

- Cultural: strengthening the ERA (European Research Area).

\section{INTERNATIONAL COOPERATION}

IASSOO (International Association of Sub-Sea Observatory Operators) related to Earth Science and Technology is being set up to implement specialised working groups:

- on standardization sensor interfaces;

- data exchange format;

- quality control procedures;

- procedures for deep-sea intervention;

- tests and calibration procedures;

- contribution to GEOSS.

All the existing projects are located in the Northern Hemisphere (Fig. 6). IASSOO will initiate contacts and cooperate with developers of observatories in the Southern Hemisphere such as CTBTO (Comprehensive nuclear-Test-Ban Treaty Organisation) [19] to gathering data at global scale in a standardised manor [20]. 


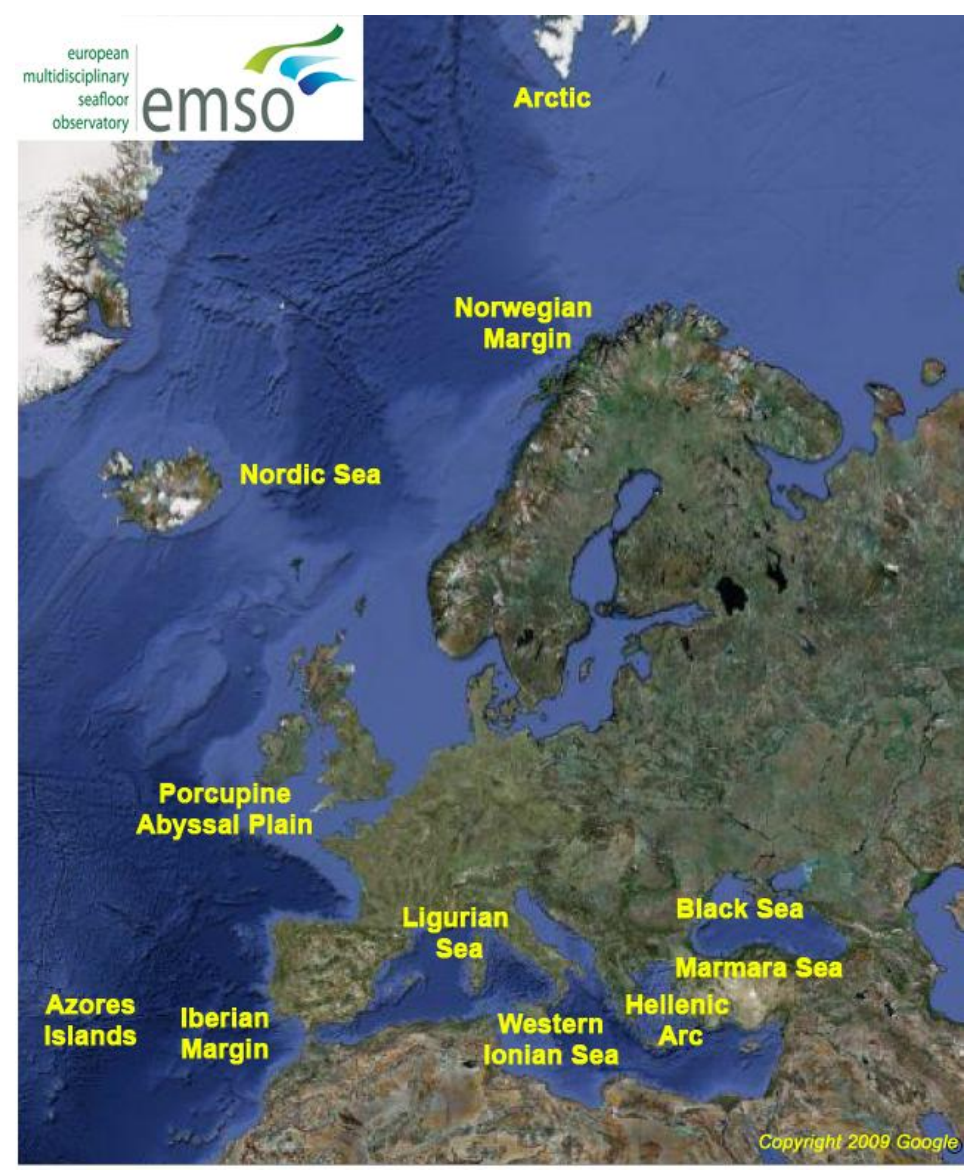

Figure 5. Map of EMSO/ESONET nodes

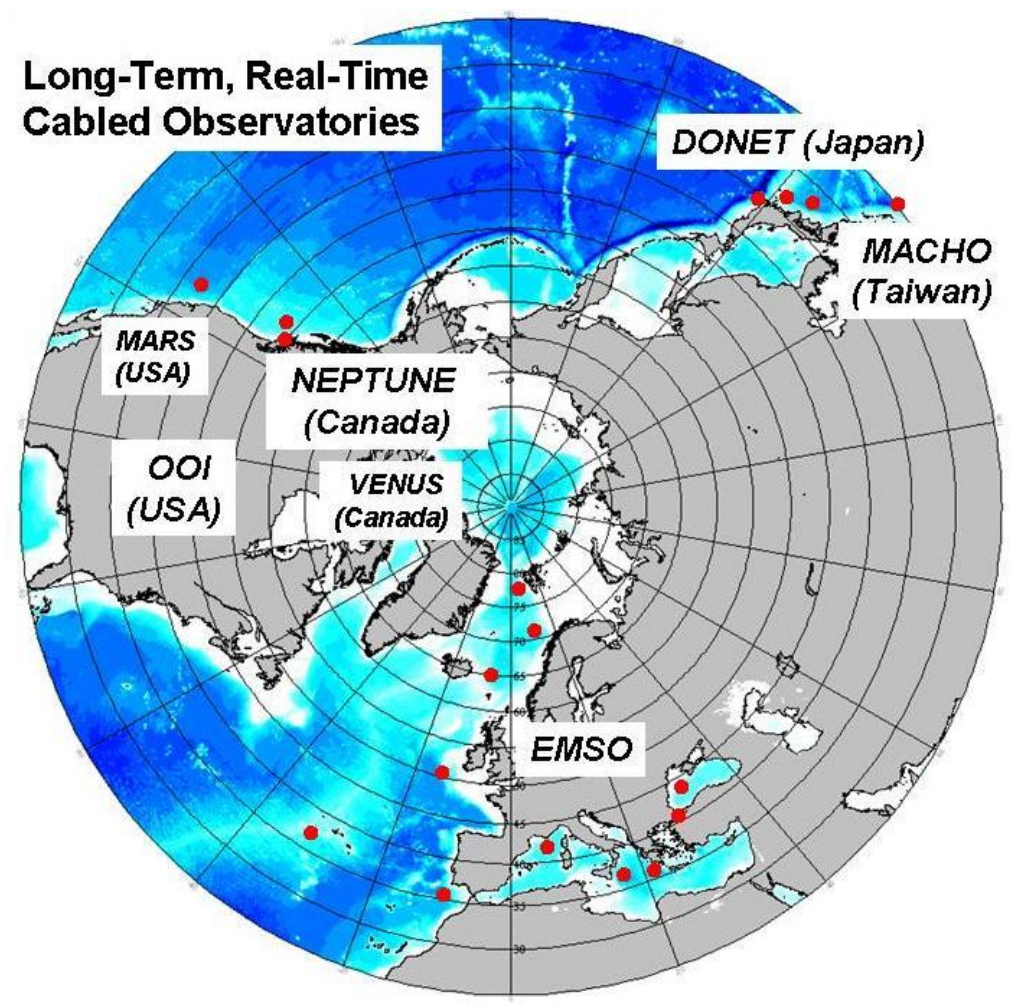

Figure 6. Running observatories projects 


\section{APPLICATIONS OF CABLED OCEAN OBSERVATORIES}

The descriptions provided above for each of the large cabled observatory systems being planned or installed around the world provide some indication of the potential applications of this technology to the ocean sciences and to other sectors. The applications go well beyond the obvious ones in ocean science research, technology and data services. Tab. 1 shows some of the other areas of application [21].

At a broader level, it is important to recognise that the advent of cabled ocean observatories heralds in a new era of ocean exploration and interpretation, which will make profound contributions to socio-economic benefits, public policy formulation, and public education and engagement. Tab. 2 summarises some of these aspects [21].

\section{SUMMARY}

The overall vision is to develop a network of interdisciplinary and multidisciplinary sustained observatories that covers the top of the ocean, the water column, the seafloor and sub-seafloor to look at the Earth as an integrated system. This novel approach represents a science and technology challenge and needs trans-national effort. As example of this vision, Fig. 7 shows the concept for a regional cabled observatory [22].

Cabled ocean observatories are rapidly becoming a reality. MARS [12] and VENUS [3] are operating successfully, with LEO-15 (Long-term Ecosystem Observatory) coastal observatory in shallow water managed by the Rutgers University [23] moving from a mainly buoyed system to adding a cable component. NEPTUNE Canada [2] and DONET [6] are going to be installed in 2009. In the European Union while the activities are continuing towards permanent installation in most of the selected sites, on the other hand EMSOPP is working to constitute the legal consortium that will manage the governance of the infrastructure (establishment and maintenance of the nodes) and will interact with the Countries interested to support the infrastructure from political and financial point of view [9]. Those observatories in Taiwan and the US are going to be installed in the next 2-5 years.

Planning is underway to establish an international association (IASSOO) to foster collaboration between the different observatories and to communicate information, progress and recommendations to contribute to GEOSS [16]. This association and individual observatories will also promote the wide use of the real-time observatory data and promote the application of the new technologies and data services within the Earth/ocean sciences and to other sectors.
- Public Policy

- Environmental

- Seismic detection

- Seafloor stability

- Tsunami detection

- Volcano monitoring

- Climate monitoring and prediction

- Conservation and protection, Marine Protected Areas

- Oceans Act

- Resources

- Biodiversity

- Fisheries

- $\quad$ Oil and Gas

- Gas hydrates

- Public health and safety

- $\quad$ Earthquake and tsunami hazard

- Volcanic hazard

- Climate change

- Algal blooms/toxicity

- Oil spills and pollution

- Marine mammals

- Security

- Transportation

- Acoustic detection

- Technology development and testing

- Port security

- Economic Development

- Growth of marine technology industry

- Innovative technologies

- Instrumentation; observing systems

- Cyber-infrastructure and data management

- Database mining

- Sub-sea operations

- Security systems

- Tourism

- National and marine parks

- $\quad$ Cruise boat industry

- Marine Mammals

- Education and Public Engagement

- Internet access to real-time data and video

- Bringing the oceans to the classrooms in realtime, student experiments

- Bringing oceans to the public/policy makers/politicians through real-time programming (e.g., media, science centres, aquaria)

- Novel expression media

- Improving public understanding of the complexity of the Earth System (e.g., marine biosphere, climate, earthquakes, tsunamis, volcanoes)

Table 1. Applications for cabled ocean observatories [21] 
- Transforming the ocean sciences

- Improved understanding of climate change

- Understanding the role of gas hydrates

- Comprehending natural hazard processes: earthquakes, tsunamis, volcanoes, slope failures

- Sustaining commercial fisheries

- Understanding ecosystem dynamics

- Monitoring ocean pollution/acidification

- Industry: ocean technologies, services, data

- Information to public, decision-makers and politicians

- Educating the next generation

- International partnerships for global networks
The establishment of a global network of observatories, covering the seafloor and the water column up to the ocean surface, will provide new data to improve our knowledge of the Earth system and to address with new information the policy for a sustainable development and environmental protection.

\section{2-ACKNOWLEDGEMENTS}

The authors gratefully acknowledge the many funding agencies that have or are supporting the observatory research and development. The summaries provided by them for each of the observatories are given on behalf of a broad community of researchers and stakeholders.

Table 2. Opportunities for cabled observatories [21]

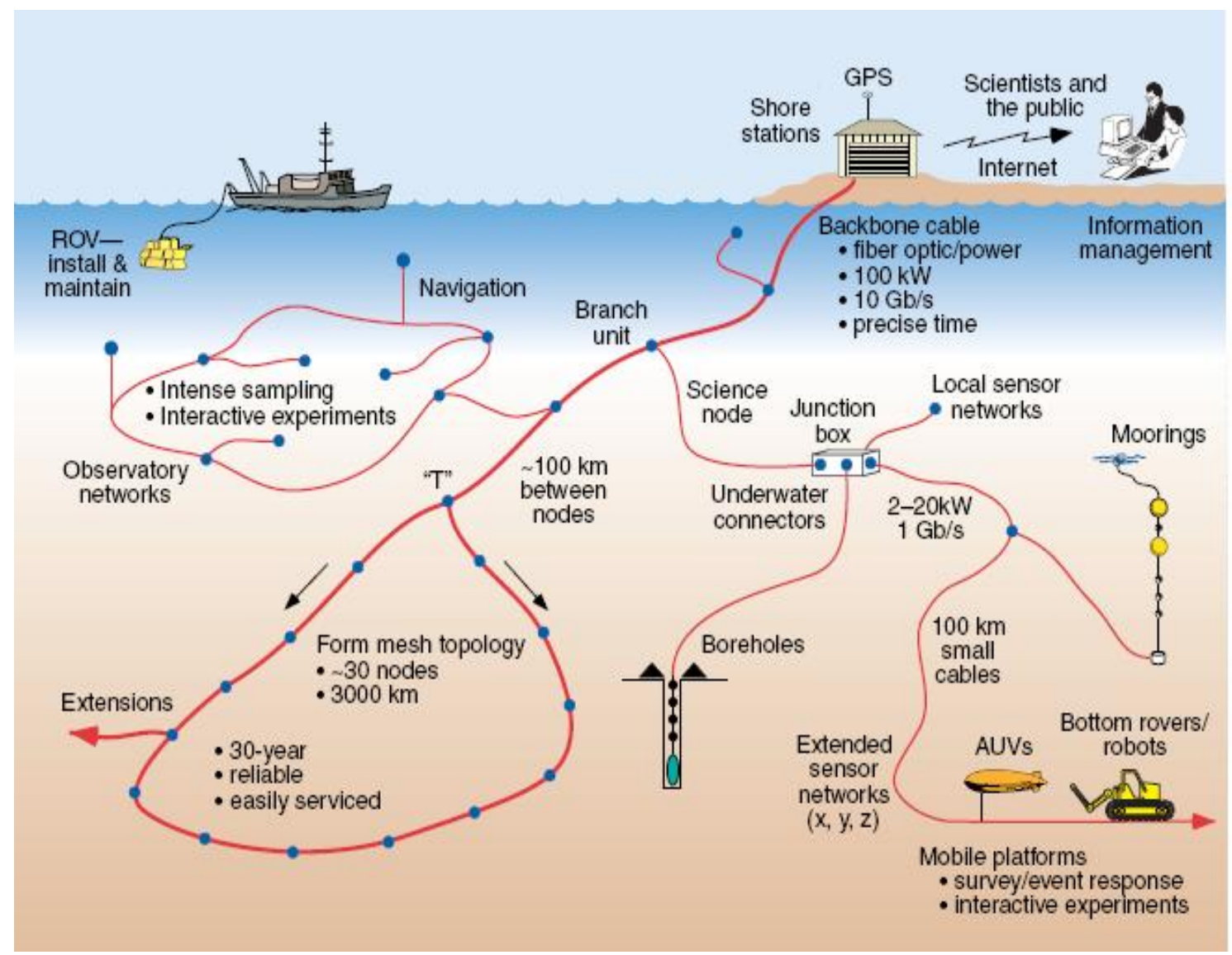

Figure 7. Concept for a regional cabled observatory [22]

\section{REFERENCES}

1. NRC (2000). Illuminating the Hidden Planet. The future of Seafloor Observatory Science, National Academy Press, Washington DC, pp.135.

2. NEPTUNE Canada http://www.neptunecanada.com/

3. VENUS http://www.venus.uvic.ca

4. OOI http://www.oceanleadership.org
5. RSN, OOI Regional component www.ooi.washington.edu/

6. DONET www.jamstec.go.jp/jamstec-e/maritec/donet/

7. MACHO http://macho.ncu.edu.tw

8. ESONET-NoE, http://www.esonet-noe.org/

9. Favali, P. \& Beranzoli, L. (2009). EMSO: European Multidisciplinary Seafloor Observatory, Nuclear Instruments and Methods in Physics Research Section A, 602, 21-27, doi:10.1016/j.nima.2008.12.214. 
10. Favali, P. \& Beranzoli, L. (2006). Seafloor Observatory Science: a review, Ann. Geophys., 49, 2/3, 515-567.

11. ONC http://www.oceannetworks.ca

12. MARS, http://www.mbari.org/mars

13. ESFRI, European Roadmap for Research Infrastructures (2008). Report 2008, ISBN 978-92-79-10117-5,

European Communities, pp. 98,

(http://cordis.europa.eu/esfri/roadmap.htm)

14. Priede, I.G., Person, R. \& Favali, P. (2005). European Seafloor Observatory Network, Sea Technology, 46/10, 45-49.

15. GMES http://www.gmes.info/

16. GEOSS http://www.earthobservations.org/geoss.shtml

17. Puillat, I., Person, R., Leveque, C., Drogou, J.-F., Diepenbroek, M., Garreau, P., Waldmann, C. \& Auffret, Y. (2009). Standardization prospective in ESONET-NoE and a possible implementation on the ANTARES Site, Nuclear Instruments and Methods in Physics Research Section A, 602, 240-245,

doi:10.1016/j.nima.2008.12.214.

18. Favali, P., Beranzoli, L., D’Anna, G., Gasparoni, F. \& Gerber, H.W. (2006). NEMO-SN1 The $1^{\text {st }}$ Real-Time Seafloor Observatory of ESONET, Nuclear Instruments and Methods in Physics Research Section A, 567/2, 462467, doi: 10.1016/j.nima.2006.05.255.

19. СТВTO Preparatory Commission http://www.ctbto.org/

20. Anichenko, A., Galindo, M., Daly, T., Castillo, E., Lastowka, L., Malakhova, M., Otsuka, R., Han, D. \& Stangel, H. (2008). Special challenges in the Operation of International Monitoring System Stations; Geophysical Research Abstracts, Vol.10, EGU2008-A12103.

21. Barnes, C R., Best, M. M. R., Johnson, F. R., Phibbs P. \& Pirenne, P. (2010). The NEPTUNE Canada Project: installing the world's first regional cabled ocean observatory. P. Favali et al. (Eds.), Praxis Publishing Co. (in press).

22. NRC (2003). Enabling Ocean Research in the $21^{\text {st }}$ Century: Implementation of a Network of Ocean Observatories, National Academy Press, Washington DC, pp. 240.

23. LEO-15 http://marine.rutgers.edu/mrs/LEO/LEO15.html 